\title{
AN ANALYSIS OF FIRST YEAR STUDENTS' GRAMMATICAL ERROR IN NARRATIVE TEXT, STIBA SARASWATI DENPASAR
}

\author{
I Wayan Eka Dian Rahmanu \\ Universitas Mahasaraswati Denpasar \\ rahmanueka@gmail.com
}

\begin{abstract}
Structure is improbable separated with the English literature and this concept should be simply applied for linguists or apprentices in English for Foreign Language and English for Second Language as well. However, in the process of presenting the text using grammar, pupils tend to make inaccurate comprehension frequently. So in this occasion, the researcher analyzed the learners' grammar mistakes in written text through narrative of 31 apprentices in STIBA Saraswati Denpasar. The method in delivering the result of this article used qualitative research which discovered and explained students' inaccurate grammar on some typical of structure. The final achievement found by the writer was that more than $50 \%$ sample of texts had mistakes on past sentences while the least number of grammar mistakes which on present perfect, simple past: be, preposition plural - singular, modal, gerund, to infinitive, passive voice and subject pronouns were slightly under $49 \%$.
\end{abstract}

Key words: Grammatical error, Narrative text

\section{Introduction}

Grammar comprehension should be known and event mastered in learning ESL/EFL as different structure would influence the meaning of the language. Linguist, expert or apprentice is suggested to learn grammar repetitively because this typical of strategy would help the learners gain the basic concepts working on literature. According to De Capua, A (2008), the term grammar frequently brings to mind tedious lessons with endless drills, repetition, and other generally mindless practice, focused on mostly obscure rules of how people are supposed to write and speak. For people who learn grammar in EFL/ESL often face some problems to apply correct grammar whether in academic or general use. On the other side, for native speakers of any given language, grammar often represents to them the great "mystery" of language, known only to language specialists or those of older generations, the ones who really know what is "right". Many feel that "grammar" is something that they were never taught and that feel they therefore "don't know." Grammar is also often linked to both explicit and implicit criticisms of people's use or "misuse" of language.

In addition, based on Knap P and Watkins M (2005), a genre-based grammar will deal with the syntactical aspects of grammar or how the language is organized within sentences; for example, the appropriate use of prepositions, plurals, articles, agreement and so on. Knowledge of grammar in this sense is not just concerned with rules for what can and can't be done with the 
organization and use of words in English sentences, but also with the way written English functions to communicate experiences and knowledge of the world. Besides that, narrative genres often deliberately break the rules of grammar and punctuation for literary effect. The process of learning narrative needs a grammatical comprehension which should be learned by the students in classroom. From this beginning process, the researcher wants to know the students ability and knowledge in the present about making a narrative text.

The background above reflected briefly that this research is aiming to analyze learners' ability in grammar especially in making a narrative text. In line of that, method of the research is qualitative which analyses the student's written text and the elaboration explains the result of the research.

Students wrote a narrative text which was examined by the lecturer is aimed to discover the grammar error done by learners. Subjects elaborated the idea using written text to retell and explain the best moment in the past. Narrative texts were submitted and checked by lecturer to figure the grammar error on the written text. From the discussions above, the researcher analyze the problems, there are: (1) the number and frequency of grammatical error found by the lecturer on the narrative text. (2) the kinds of grammatical error done by the students in making narrative text in the classroom.

\section{Result and Discussion}

Writing narrative text should use past tense to explain the learners' previous experience where students must concern to use verb past as the indication. Furthermore, the researcher found about nine more grammatical errors beside past tense written by the learners for example: present perfect, simple past: be, preposition plural singular modal, gerund, to infinitive, passive voice and subject pronouns, these can be seen from the diagram below which shows the grammatical error written by the students that would be elaborated as follow.

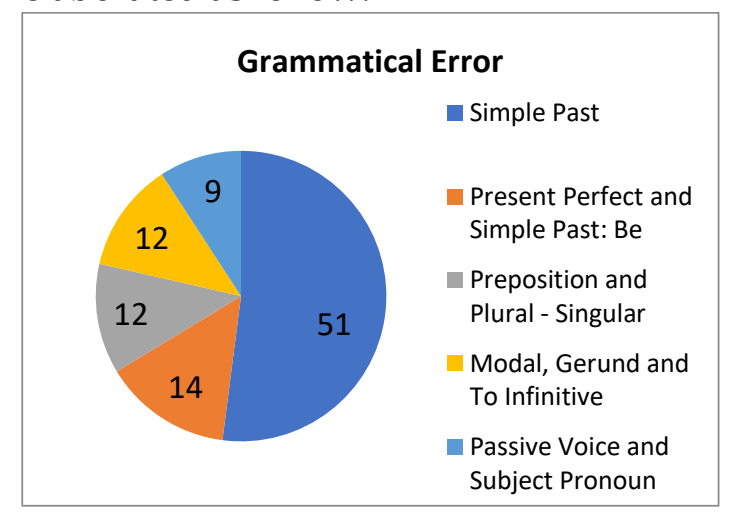

The diagram above illustrates the structure error in 10 types of grammar (simple past, present perfect, simple past: be, preposition plural - singular, modal, gerund, to infinitive, passive voice and subject pronouns) done by the apprentice in the first year University.

Overall, the most grammatical error written by the students in making narrative text was on simple past while the learners made more mistakes on present perfect and simple past: be than preposition and plural - singular and modal gerund and to infinitive whereas the least number mistakes written by the pupils was on passive voice and subject pronoun.

The final achievement found by the writer was that more than $50 \%$ sample of texts had mistakes on past sentences while the least number of 
grammar mistakes which on present perfect, simple past: be, preposition plural - singular, modal, gerund, to infinitive, passive voice and subject pronouns were slightly under $49 \%$.

With regards to the number of simple past tense, there were slightly more than 50 grammatical errors written by the learners compare to the simple present perfect and simple past: be were below 20 number of errors.

On the other hand, inaccurate grammar between prepositions, plural singular and modal, gerund, also infinitive had similar number around 12 errors while the least number of inaccurate structures was on the combination of passive voice and subject at under 10 numbers.

\section{Simple Past Regular and Irregular Verbs Error}

The simple past was applied to talk about activities or situation that began and ended in the past, Betty Azhar (2003). This means that the action should be done in the previous time where the form of simple pasts are added by "-ed" mostly and some verbs have irregular past forms. In adding "-ed" in regular and irregular form, there are some grammatical errors done by the learners in writing several sentences in a paragraph. The result of regular and irregular verb could be seen from the graph below.

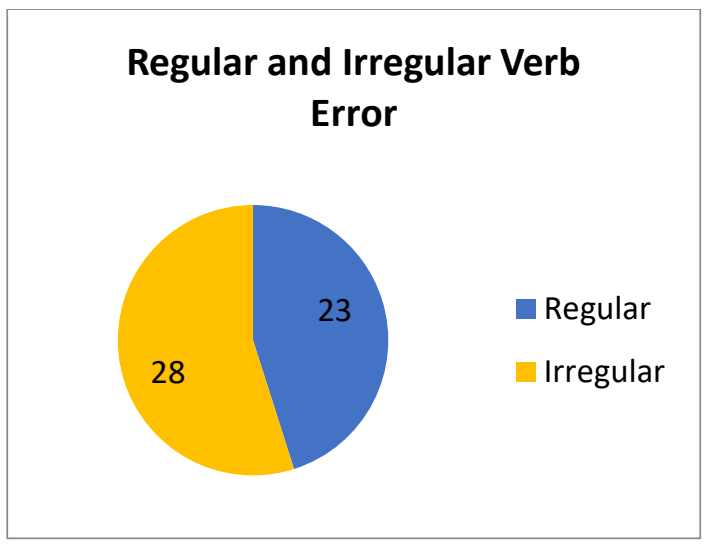

The graph illustrates the number of regular and irregular verb mistakes written by the apprentice.

Overall, the students made more mistakes on irregular than regular verb. Besides that, students did significant numbers of incorrect grammar in making narrative text during the class room activities.

In terms of irregular inaccuracy, learners made exactly 28 of structure errors as it was slightly more than the total number of regular verb which was 23 number of grammar error where both typical simple past can be explain as follow.

a. Regular Verb

Regular form for example "My sister try to swing ...", the verb "try" follows subject "my sister" where the situation was in the past, so the use of "try" was totally incorrect, the learner should use "tried" as the verb past. Furthermore, where the learner made a sentence "my father and my mother play sands.", the verb should be "played" as past tense condition because the word "played" was a past form of verb play. Another identical mistake for instance "Me and my family waiting ...", this sentence was a simple sentence but irrelevant as the topic was the narrative 
text because the text needed a past verb to make grammatically correct and verb past "waited" should be needed after subject. Another grammar error was written such as "I want to stay at Inna Grand Bali beach ...", the verb "want" suppose to be "wanted" as a past tense representative. Moreover, verb past "changed" must be used to make the appropriate sentence in "I change my clothes", the student used verb present to make the sentence as it would be wrong form in making a narrative text. In "I walk around the hotel until night" example, the verb past "walked" should replace because "walk" was a mistake in making a past written text. Besides, the example in "I really enjoy when ...", the verb past "enjoyed" should be applied as this was the past form of "enjoy", the same error could be seen in "my dad and I stay in my dad ..." where verb "stay" was inappropriate choice in making a past form as "stayed" should be applied by the learner. In line of that, an example in "I pray in Lempuyang Temple..." was completely a present form because the verb past "prayed" was required as the context of the sentence was past tense. Furthermore, the sentence in "I provide many foods and drinks" should use "provided" as the verb past to reflect the sentence in the past. The subject " $I$ " should be followed by "visited" because the error could be seen from the example in "I visit Thailand with my family" where the verb present was used in the sentence. Similarly, the verb in the sentence "we visiting tourist spot in Nusa Penida" should not be a verb "-ing" but "visited" where this would support "we" was a subject in the sentence. The researcher also found "We rent..." where the "rented" must be used to make a relevant past form in elaborating a narrative text. The verb past "decided" was an obligation in making an example of this sample: "I decide to choose this moment because ..." this illustration was an error because the student used verb present "decide" where the correct verb should be verb past "decided". The "needed" was automatically used when we write past tense in "we need to pay the entrance ticket ..." however the student still made a mistake in choosing a verb past. Similarly, in two examples of grammatical error for instance "we relax in the hotel after ..." and "we enter the temple ..." was correct if the context was in present tense but the reader should be consistent in making a narrative text where this needs verb past "relaxed" and "entered" respectively. Miss understanding in using past tense was also sometimes makes the learners hesitate to use past verb in the sentence "I have booked a very beautiful villa" was a present perfect form tense where the verb should be "booked" not "have booked". In line of that, miss interpreting of passive voice could be also seen in the learners written text for example: "We are stayed at Sukapura Hotel" this sentence did not reflect the situation of narrative text because to be "are" should not be written as the context of the sentence or paragraph which was a past tense not a passive voice form. Besides, similar mistake could be discovered in the next example of sentence such as "I was visited this place before", the sentence was a passive voice form which was used by the apprentice where the miss understanding of using to be and verb participle was done by the leaner. The 
last example "I was started the journey at 3 o'clock" definitely a passive voice form where the form could be used if reasonable however the reader would be misinterpret if this example of sentence written by the student because "was started" should be "started". Henceforth, the learner wrote "we was stay in Maya Ubud Resort" where "was" should not be put after subject, this was wrong interpretation because after " $w e$ " must be followed by "stayed" as the form of verb past. The student had a mistake in choosing a word "I celebration $17^{\text {th }}$ birthday" where the word "celebration" was a noun however in this situation, the student must choose "celebrated" as represent a present tense.

\section{b. Irregular Verb}

On the other hand, Irregular verb should be known by learners in studying English grammar as the pattern of the appropriate linguistics and literary. However, researcher discovered some mistakes done by the students in the first year in the University such as "I am with my friend eat at...", this sentence has exactly grammar error in irregular verb point of view, the verb past "ate" should be written. The other words, the writer also found several mistakes done by the students in irregular verb aspects such as "I go to Anorra beach with my family..." and "at night, I go to outside hotel to find..." the verb past "went" should be applied in these two sentences to make grammatically correct and appropriate structure. In line of that, the researcher still found basic mistake written by the apprentice, in the sentence of "my mom and dad give me ticket to stay..." and "but on my birthday, my mom give me ticket to stay there", from these two mistakes, the choice to choose the verb "gave" was not really difficult because this verb past was very familiar for the English foreign language learner. Practically, apprentice ignored the use of verb past to make a complete sentence where the sentence needs at least subject, predicate and object. This was neglected by the learners where the learner made "me and my family dinner ..." and "yesterday, I holiday in Padang - Padang Beach", the sentence needs verb past " $g o t$ " to make a complete sentence after subject "me and my family". Selecting "slept" as the past verb in "after that I sleep at hotel until the day after" was a must therefore "slept" was a past form to make a consistent situation. Furthermore, the learner still put to be "am" while making a past tense where this would be a fatal mistake and the examples are "I am holiday to Bedugul" and "I am go Bedugul...", in the two examples, there are ambiguity written by the apprentice the sentence "I am holiday to Bedugul" could not be interpreted correctly in grammar point of view where the sentence would be accepted if the sentence was "I spent my holiday to go to Bedugul" as this would be acceptable in grammar. In line with that, "am" was not needed in "I am go to Bedugul..." because the context was ended in the past so, the sentence must be "I went to Bedugul...". Other example of irregular verbs which should be used by the learner was in "I buy strawberry and I am buy snack...", there two clauses in the sentence where the first was "I buy strawberry" and the second clause was "I am buy snack". There are two mistakes done by the student in making the clauses, the verb "buy" should be "bought" and "Iam buy" in the 
second clause must be omitted as this was a repetition and the correct sentence should be "I bought strawberry and snack". Two clauses in a sentence was also found in "we only share and make a quality time with big family", the first would be "we only share a quality time with a big family" and the second clause was "we only make a quality time with a big family" however, the use of verbs were still wrong as the situation and condition of the sentence was in the past, the verb should be "shared" and "made" respectively. Besides that, the example in choosing "took" as the verb past where the student still used "take" and the sample was "my friends and my family take a picture because...", close to the previous sample, in "we are taked a picture", the learner write passive voice and this sounds ambiguous where in grammatical should be "we took a picture", furthermore the apprentice write "taked" where the writer might think "take" was a regular verb. Exactly the same with the previous example, the writer found a mistake in "my parents gived me notice..." where the student thought "gived" was the verb past of "give" while the correct was "gave". Miss understanding in writing past tense in a sentence also found by the researcher and this could be proved in "we spend our time on the way about less than 3 hours", the writer tended using "spend" instead of "spent" while this past verb was correct in grammatical. Surprisingly, the learner chose and used verb participle in making a simple past tense this could be seen in "on the way to Amed, we seen..." the appropriate verb should be "saw" however the learner used "seen" where this was a totally incorrect. Similarly, verb participles were also applied by the apprentice in "I seen many beautiful corals..." and "we seen many beautiful place such as..." where these two examples are completely grammatically error because the verb used was "seen" as the correct verb should be "saw" as the verb past. In addition, the example in "In Pasar Agung Temple I see the animals..." could be found that "see" was not accepted as "saw" would be the perfect grammatically correct based on the situation and the story written by the student. As researcher found in "we sing together...", the mistake was still choosing the correct verb where the learner tend to use verb present "sing" than "sang" as the perfect grammar. Likewise, the sentences "I drink a glass of wine", "I spend one day with my beloved people" and "we swim together" contain inaccurate verbs written by the student which could be seen from the verb "drink", "spend" and "swim" must be "drank", "spent" and "swam" respectively. Another example of sentence found by the researcher shows identical grammar error such as "we take a picture, relax and meet with friend", there are three verbs found in this sentence which have incorrect grammar, "take", "relax" and "meet" the verb present should be changed as the function was for past form: "took", "relax" and "meet" simply reflect the verb past to get the grammar correct. Students also lack in understanding the use of "-ing" which was used for continuous, the simple past form should use verb past to explain the subject in a sentence. The example such as "we having breakfast together at eight o'clock' shows the lack of student's comprehension on grammar in using verb "-ing" particularly. The verb "having" should be "had" as the past 
form. In line of that, the writer also found similar error in "my mom have to meet her partner in working place" which must be "had" because the form of the verb was a past.

Those regular and irregular verb mistakes and errors are frequently done by the learners, where the apprentice consistently was applied during the writing narrative text.

\section{Present Perfect}

Present perfect expresses an activity or situation occurred or did not occur before now, at some unspecified time in the past, Betty Azhar (2003). This means perfect tense could be explained that an action or actions that were happened or did not happen in the previous time unlisted. In the activity of making a narrative text, the writer also found the mistake of using perfect tense during the learning activities which could be seen for example "I ever been visited the most beautiful lake...". This sample of error used "been" which this was a passive voice where the correct grammar was "I have visited the most beautiful lake..." as the situation and condition was in the past.

\section{Simple Past: Be}

According to Betty Azhar (2003), simple past be apply was or were after the subject and before adjective or adverb. "Was" follows subject" $I$, she, he, it or singular" in the other hand, "were" come with "they, you, we or plural". There were some errors in putting simple past: be in several sentences. The first example was "I went there when I were..." there are two clauses in this sentence was "I went there" and the second clause can be seen as "I were" the learner made the first clause perfectly however the mistake found when the student used "were" after subject " $I$ " where the subject suppose to be followed by "was". The other examples, researcher found that the learner applied present be in a past tense context the explicit example are "the surprise is my mom and dad...", "that is the best moment of my life" and "... because the place is really fresh". These three grammatical errors are clearly seen that "is" used by apprentice in these two sentences. The correct grammar should be "was". Besides that, the learner did not apply past "be" in the next three sentences as the students tended to ignore the use of "was", these five grammatical errors could be seen as follow: "I there feel like heaven" where after subject " $I$ " should be followed by "was". The second sample was "the ticket not too expensive only $R p 20.000$ ", in this example, verb past: "was" should be used by the student before " $R p$ 20.000" because this was an adverb. The third sentence was "... when I there because the place", ignoring "was" was definitely a mistake done by the leaner as this was the structure of English and the fourth example was "... by car and I as driver", verb past "was" should follow " $I$ " as a subject in the sentence. Neglecting "was" was also the student's weaknesses, this could be perceived in a sentence such as "I very happy..." the word happywasan adjective which should be follow by to be "was" because the context was in the past. Furthermore, the writer also found miss concept used by the students in two example of sentences, there are in "when I'm in the last grade in junior high school..." and "yesterday, I'm happy" in these two 
examples, "am" was still used by the students where this must be "was" as the situation was in the past. The last two mistakes written by the apprentice were "we are very lucky the weather become sunny" and "we so happy, we must go..." the first sentence has clearly grammatical error where the student wrote "are" instead of "were" and in the second sentence, the learner ignored the verb be "were" as the representation of past tense in making a narrative text.

\section{Preposition}

Based on Cowan, R (2008), the position of occurrence for English prepositions typically described in grammar and English for Second Language or English for Foreign Language textbooks were at the head of a prepositional phrase which was before the head noun of a noun phrase. Typical example of prepositional phrases made up a preposition and an object are "in the afternoon" and "on the table". The example found by the researcher was "we arrived at change airport at morning and met my mom's friend" where typical preposition used illustrates inaccurate because the correct was "in the morning".

\section{Plural - Singular}

English nouns generally present few problems for the advanced learners however some aspects of count ability and noun verb agreement can be problematic, Foley M and Hall D (2003). This could be argued that upper intermediate apprentice would face difficulties in some specific part of singular and plural noun. The researcher found some evidences which represent the previous statement where the learners made some grammatical error in plural and singular nouns such as "six month ago I went to Beratan Lake with my sister", this sample of statement has a definitely correct in verb past "went" however containing a mistake plural noun which was "month" as the noun suppose to be "months". Moreover, in a sentence "we seen many beautiful place such as...", there are two inaccuracies done by the learner, "seen" which discussed by the writer in the irregular verb error and a noun "place" should be "places" to emphasize "many" as more than one things. The lack of irregular plural noun was also shown in the next example such as "the local peoples here use crabs for fishing", singular the noun "people" was "person" as the letter " $s$ " was not needed to make a plural noun. In line of that, the writer also found similar inappropriate grammar in making some sentences. There are three more transgressions done by the students such as "I went to some restaurant in Java", "I bought some souvenir..." and "we saw many plants and statue". Al examples have exactly similar error where each example has correct past verb "went", bought" and "saw" however the nouns are mistaken, these could be seen such as "restaurant" because "some" as plural representation and the noun should be "restaurants", in line of that, the second and the third sentence, the noun should be "souvenir" and "statues" respectively. The other grammatical error was "we ordered 2 ticket Bali Zoo from Traveloka" where "ticket" should be "tickets" as the statement mention more than one ticket. Identically with the previous error, the noun in "... Lempuyang Temple 1 years ago" should be 
a singular without letter " $s$ " after the noun "year".

The last two examples definitely clear that the learner wrote a mistake plural noun, there are "I got many experience at the time ..." and "there are 5 person" where "experiences" and "people" should be written as "many" and "5" indicate the noun should be plural these two singular and plural error that must not be ignore by the students in learning grammar.

\section{Modal}

Modal was used to ability and possibility, to make deductions, arrangements, suggestions and offers and to ask for and give permission, Foley $M$ and Hall D (2003). However, in written text this can be confusing because if the verb after modal should be a verb present. Besides that, modal should be follow past tense structure if the situation and condition was happened before. The example of grammatical error in modal in "I can find a lot of accessories..." where modal must be "could" to illustrate past tense. Nevertheless, if modal was followed by verb, the verb should be verb infinitive and learners ignore this frequently, the lack of grammar could influence the structure of a sentence, some students wrote wrong grammar such as "... and also I can saw a Balinese dance", "you can also playing football...", "we must to buy ticket small boat ..." and "we must waiting 20 percent people because...". The four inaccurate grammatical sentences written by the apprentice should be "see" instead of "saw", "play" without "-ing", "to buy" was not properly when a modal before "must" as the verb should be infinitive, furthermore verb -ing was not permitted after modal.

\section{Gerund}

Based on Betty Azhar (2003), Gerund was the "ing" of a verb and it was used as a noun. However students were still getting problem in using gerund to make a sentence, the example was "In Lempuyang Temple I cannot stop take picture" after verb "stop" the word take should be "taking" as used a noun. Besides, a preposition was also followed by gerund for example for, in, at, on and from but the students made a inaccuracy to make the correct structure such as "we booked a room for slept but..." the verb past "booked" was clearly accepted in grammar point of view however after preposition for, sleeping must be the correct gerund. Similarly, the researcher also found mistake in applying gerund in last two sentences for instance "... for find good place in Bedugul..." and "... Bedugul area for sit..." in this sentence, "finding" and "sitting" should follow preposition "for" respectively.

\section{To infinitive}

Discussing about to infinitive, Foley M and Hall D (2003) mentioned that infinitive with " $t o$ " can be the subject, object or complement of a verb. Practically, the writer found several mistakes in applying to infinitive in the narrative text activities. There are three miss interpretations used by the apprentice for instance "my first time to explored Ubud", "My mom's friend invited us to having dinner..." and "... because this place was so nature and make me want to stayed" where the error in the first example should be changed as "to 
explore", the mistake in the second sentence must be replaced as "to have" and the wrong grammar in the last example have to be "to stay".

\section{Passive voice}

Based on Cowan, R (2008), passive sentences frequently occur in news reports and, as previously noted academic writing. As a result these are often emphasized in English for Second language writing courses. From the previous statement, it means that passive voice commonly used in written text. Compare to regular and irregular sentences, the apprentice tended to use passive voice fewer, the researcher only found three example of passive voice for instance "I'm very excited...", "kebun raya Bedugul located in Tabanan" and "Amed is very beautiful place that located in East of Bali". the first example which was "I' $m$ very excited..." has an error verb past: be, as the correct was "I was very excited...". The second example: "kebun raya Bedugul located in Tabanan" was slightly correct however to make a good passive voice the sentence must be "kebun raya Bedugul is located in Tabanan" because "is" should be written before located as the requirement of passive voice.

\section{Subject pronoun}

According to Cowan, R (2008), pronouns are grammatical forms that substitute in some way for an entire clause. The typical replacement such as she, he, it, they and we. In analyzing the learners' narrative text, there are two evidences which prove errors such as "until us arrive in Kedonganan..." and "so her not like the view..." from the first sentence the student wrote " $u s$ " that it 56 should be "we" and used "her" which the accurate subject pronouns was "she" for the second example.

\section{Conclusion}

Pupils had difficulties in choosing the right and proper grammar during writing the narrative text especially. On the other hand, the lack of comprehension on structure was the effect to get inaccuracy in selecting suitable grammar. However, these issues can be solved by giving repetition the rule of grammar. Drilling strategy would help to increase students' achievement in getting better score in writing narrative text especially and English writing text commonly.

The concept of written text even narrative text in English which was used past tense should be thought frequently by the lecturer in the classroom as this was the most grammatical error found by researcher obviously. Furthermore, drilling method could be applied as this method is a repetition process. The lecturer is also proposed to apply students' daily activities while discussing grammar lesson because the learner could understand the situation correctly. Moreover, apprentice must penetrate grammar repeatedly to increase the comprehension of the English structure.

\section{References}

Betty Azhar. 2003. Fundamental of English Grammar. Longman: New York.

Cowan, R. 2008: The Teacher's Grammar of English. Cambridge university press: New York.

DeCapua, A. 2008: Grammar for Teachers A guide to American English for Native and Non-native Speaker. Springer: New York. 
Foley M and Hall D. 2003: Advanced Learners' Grammar. Longman: China.

Knap P and Watkins M. 2005: Genre, Text, Grammar - Technologies for Teaching and Assessing Writing. University of New South Wales: Australia. 